\title{
A T-Shaped Three-Coordinate Nickel(I) Carbonyl Complex and the Geometric Preferences of Three-Coordinate $\mathrm{d}^{9}$ Complexes
}

\author{
Nathan A. Eckert, ${ }^{\dagger}$ Adriana Dinescu, ${ }^{\ddagger}$ Thomas R. Cundari, ${ }^{*}, \neq$ and Patrick L. Holland ${ }^{\star, \dagger}$ \\ Department of Chemistry, University of Rochester, Rochester, New York 14267, and Department \\ of Chemistry, University of North Texas, Denton, Texas 76203
}

Received June 22, 2005

A three-coordinate diketiminate-nickel(I) complex with a carbonyl ligand has been characterized using EPR and IR spectroscopies and X-ray crystallography. The $T$ geometry (bending from the sterically favored $C_{2 v}$ structure) contrasts with that of isosteric $d^{9}$ copper(II) complexes. DFT calculations on a truncated model reproduce experimental geometries, implying that the geometric differences are electronic in nature. Analysis of the charge distribution in the complexes shows that the geometry of the threecoordinate $d^{9}$ complexes is affected by differential charge donation of the ligands to the metal center.

Three-coordinate complexes of transition metals with partially filled $d$ shells have received attention because of their unusual reactivity and electronic structure. ${ }^{1}$ The predominant geometry in crystallographically characterized three-coordinate complexes is trigonal-planar, with the ligands symmetrically distributed to minimize steric effects. The main exception to this generalization is with low-spin $\mathrm{d}^{8}$ systems, which clearly favor a T-shaped geometry. ${ }^{2}$

In recent papers, we described the synthesis and electronic structure of a series of three-coordinate complexes with $\mathrm{d}^{6}$, $\mathrm{d}^{7}, \mathrm{~d}^{8}$, and $\mathrm{d}^{9}$ electronic configurations at the metal center. ${ }^{3,4}$ A bulky $\beta$-diketiminate ligand ("L") was used, and a sterically favored $Y$ geometry was evident at the metal in each case. In the $\mathrm{Y}$ geometry, the nickel coordination environment is idealized $C_{2 v}$, with the non-diketiminate ligand on both mirror planes. The $\mathrm{d}^{9}$ example, $\mathrm{L}^{\mathrm{tBu}} \mathrm{Ni}(\mathrm{THF})$ (Figure 1, left), is notable because there are few examples of isolable three-coordinate nickel(I) complexes, ${ }^{5}$ one series of three-coordinate copper(II) complexes, ${ }^{6}$ and no threecoordinate $\mathrm{d}^{9}$ complexes of heavier metals. Understanding

* To whom correspondence should be addressed. E-mail: tomc@unt.edu (T.R.C.), holland@chem.rochester.edu (P.L.H.).

University of Rochester.

$\doteqdot$ University of North Texas.

(1) Cummins, C. C. Prog. Inorg. Chem. 1998, 47, 685.

(2) (a) Komiya, S.; Albright, T. A.; Hoffmann, R.; Kochi, J. K. J. Am. Chem. Soc. 1976, 98, 7255. (b) Yared, Y. W.; Miles, S. L.; Bau, R.; Reed, C. A. J. Am. Chem. Soc. 1978, 99, 7076.

(3) Smith, J. M.; Lachicotte, R. J.; Holland, P. L. Chem. Commun. 2001, 1542.

(4) Holland, P. L.; Cundari, T. R.; Perez, L. L.; Eckert, N. A.; Lachicotte, R. J. J. Am. Chem. Soc. 2002, 124, 14416.

7702 Inorganic Chemistry, Vol. 44, No. 22, 2005

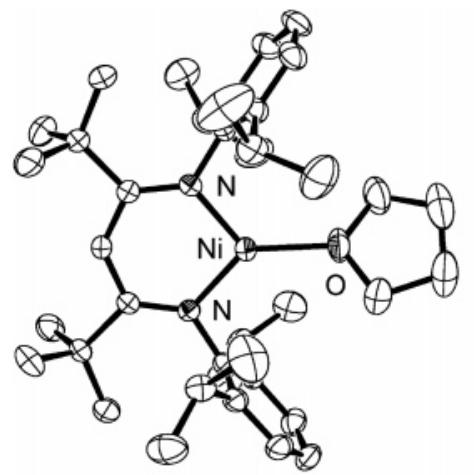

$\mathrm{L}^{\mathrm{tBu}} \mathrm{Ni}(\mathrm{THF})$

Y geometry idealized $C_{2 v}$

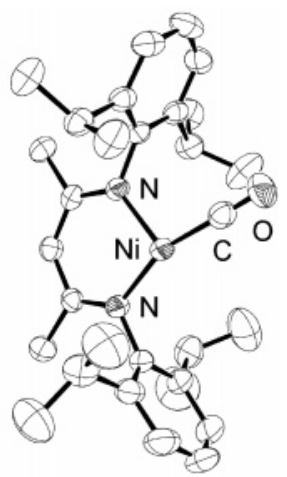

$\mathrm{L}^{\mathrm{Me}} \mathrm{Ni}(\mathrm{CO})$

T geometry

idealized $C_{\mathrm{s}}$
Figure 1. Synthesis and thermal-ellipsoid plots of $\mathrm{L}^{\mathrm{tBu}} \mathrm{Ni}(\mathrm{THF})^{4}$ and $\mathrm{L}^{\mathrm{Me}}$ $\mathrm{Ni}(\mathrm{CO})$. Ellipsoids are at $50 \%$ probability, and hydrogen atoms are omitted for clarity.

of three-coordinate nickel(I) complexes is also biologically relevant because three-coordination is potentially accessible in the low-coordinate "proximal" nickel site of acetylcoenzyme A synthase (where methylcobalamin, $\mathrm{CO}$, and coenzyme A are transformed into acetyl-coenzyme A). ${ }^{7}$ Below, we use synthetic, crystallographic, and theoretical studies to show that the first three-coordinate nickel(I) carbonyl complex prefers a $T$ geometry. We compare it to relevant nickel(I) and copper(II) complexes to arrive at new

(5) (a) Bradley, D. C.; Hursthouse, M. B.; Smallwood, R. J.; Welch, A. J. J. Chem. Soc., Chem. Commun. 1972, 872. (b) Nilges, M. J.; Barefield, E. K.; Belford, R. L.; Davis, P. H. J. Am. Chem. Soc. 1977 99, 755. (c) Ellis, D. D.; Spek, A. L. Acta Crystallogr. 2000, C56, 1067. (d) Eaborn, C.; Hill, M. S.; Hitchcock, P. B.; Smith, J. D. Chem. Commun. 2000, 691. (e) Mindiola, D. J.; Hillhouse, G. L. J. Am. Chem. Soc. 2001, 123, 4623. (f) Melenkivitz, R.; Mindiola, D. J.; Hillhouse, G. L. J. Am. Chem. Soc. 2002, 124, 3846. (g) Kitiachvili, K. D.; Mindiola, D. J.; Hillhouse, G. L. J. Am. Chem. Soc. 2004, 126, 10554. (h) Kogut, E.; Wiencko, H. L.; Zhang, L.; Cordeau, D. E.; Warren, T. H. J. Am. Chem. Soc. 2005, 127, 11248.

(6) (a) Holland, P. L.; Tolman, W. B. J. Am. Chem. Soc. 1999, 121, 7270. (b) Holland, P. L.; Tolman, W. B. J. Am. Chem. Soc. 2000, 122, 6331 (c) Randall, D. W.; DeBeer George, S.; Holland, P. L.; Hedman, B.; Hodgson, K. O.; Tolman, W. B.; Solomon, E. I. J. Am. Chem. Soc. 2000, 122, 11632. (d) Jazdzewski, B. A.; Holland, P. L.; Pink, M.; Young, V. G., Jr.; Spencer, D. J. E.; Tolman, W. B. Inorg. Chem. 2001, 40, 6097. 


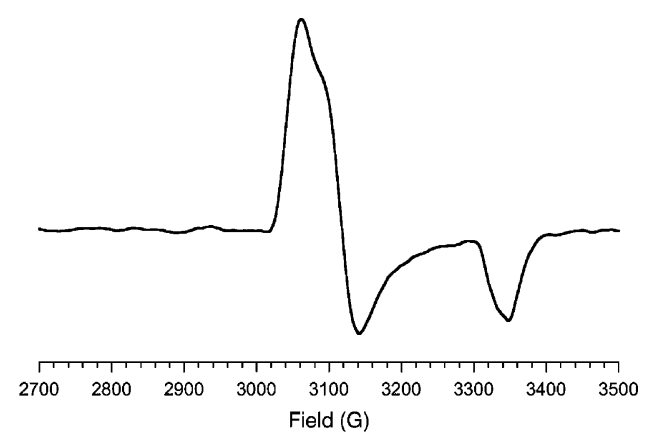

Figure 2. EPR spectrum of $\mathrm{L}^{\mathrm{Me}} \mathrm{Ni}(\mathrm{CO})$ at $9.429 \mathrm{GHz}$.

insights into the electronic and steric factors underlying the preferred geometries of three-coordinate $\mathrm{d}^{9}$ complexes.

We previously reported that reaction of a THF solution of the nickel(II) complex $\mathrm{L}^{\mathrm{tBu}} \mathrm{NiCl}$ with methyllithium yielded the isolable reduction product $\mathrm{L}^{\mathrm{tBu}} \mathrm{Ni}(\mathrm{THF}$ ) (Figure 1 , left). ${ }^{4}$ The analogous reduction of $\left[\mathrm{L}^{\mathrm{Me}} \mathrm{NiCl}\right]_{2}{ }^{8}$ in diethyl ether followed by treatment with excess carbon monoxide gives a red solution, from which $\mathrm{L}^{\mathrm{Me}} \mathrm{Ni}(\mathrm{CO})$ can be isolated in $61 \%$ yield. The spectroscopic properties of $\mathrm{L}^{\mathrm{Me}} \mathrm{Ni}(\mathrm{CO})$ are consistent with the $\mathrm{d}^{9}$ electronic configuration. $\mathrm{L}^{\mathrm{Me}} \mathrm{Ni}$ (CO) has only broad peaks in its ${ }^{1} \mathrm{H}$ NMR spectrum, and its $\mathrm{X}$-band EPR spectrum (Figure 2) shows a slightly rhombic signal with $g$ values of 2.19, 2.17, and 2.01. Its IR spectrum shows a band at $2022 \mathrm{~cm}^{-1}$, which indicates the presence of one CO ligand.

Because $\mathrm{L}^{\mathrm{tBu}} \mathrm{Ni}(\mathrm{THF})$ and the isosteric $\mathrm{d}^{9}$ complex $\mathrm{L}^{\mathrm{Me}}$ $\mathrm{CuCl}^{6 \mathrm{a}}$ have $\mathrm{Y}$ geometries, we expected a similar geometry for the carbonyl complex. However, the X-ray crystal structure shows that $\mathrm{L}^{\mathrm{Me}} \mathrm{Ni}(\mathrm{CO})$ has a $\mathrm{T}$ geometry, with $\mathrm{N}-\mathrm{Ni}-\mathrm{C}$ angles of $104.6(1)^{\circ}$ and $158.9(1)^{\circ}$ (Figure 1, right). The $\mathrm{Ni}(\mathrm{I})$ coordination geometry is planar (sum of bond angles $=359.9(2)^{\circ}$; Ni lies 0.020(1) $\AA$ from the NNC plane). The strong trans influence of the carbonyl ligand gives a longer $\mathrm{Ni}-\mathrm{N}$ bond distance trans to $\mathrm{CO}[1.917(2)$ vs 1.868 (2) $\AA$ ] . Consistent with the relatively weak back-bonding inferred from IR spectroscopy, the $\mathrm{C}-\mathrm{O}$ bond length of $1.142(3) \AA$ is only slightly longer than that in free CO $(1.128$ $\AA) .{ }^{9}$ The $\mathrm{Ni}-\mathrm{C}$ distance of $1.770(3) \AA$ is similar to fourcoordinate $\left[\mathrm{PhTt}^{\mathrm{Bu}}\right] \mathrm{Ni}(\mathrm{CO})\left[\mathrm{Ni}-\mathrm{C}=1.754(7) \AA{ }^{10}\right.$

To determine whether the $\mathrm{T}$ geometry arises from electronic effects, we queried the energy and geometry of $\mathrm{L}^{\prime} \mathrm{Ni}-$ (CO), in which $\mathrm{L}^{\prime}$ represents the truncated diketiminate $\mathrm{N}_{2} \mathrm{C}_{3} \mathrm{H}_{5}$, using density functional theory (DFT) at the

(7) Structural review: (a) Drennan, C. L.; Doukov, T. I.; Ragsdale, S. W. J. Biol. Inorg. Chem. 2004, 9, 511. Mechanistic review: (b) Hegg, E. L. Acc. Chem. Res. 2004, 37, 775. Calculations: (c) Schenker, R. P.; Brunold, T. C. J. Am. Chem. Soc. 2003, 125, 13962. (d) Webster, C. E.; Darensbourg, M. Y.; Lindahl, P. A.; Hall, M. B. J. Am. Chem. Soc. 2004, 126, 3410. (e) Amara, P.; Volbeda, A.; Fontecilla-Camps, J. C.; Field, M. J. J. Am. Chem. Soc. 2005, 127, 2776. Evidence for a kinetically competent nickel(I) carbonyl intermediate: George, S. J.; Seravalli, J.; Ragsdale, S. W. J. Am. Chem. Soc. 2005, 127, 1350013501.

(8) Eckert, N. A.; Bones, E. M.; Lachicotte, R. J.; Holland, P. L. Inorg. Chem. 2003, 42, 1720.

(9) National Institute of Standards and Technology. http://webbook.nist.gov/chemistry/.

(10) Schebler, P. J.; Mandimutsira, B. S.; Riordan, C. G.; Liable-Sands, L. M.; Incarvito, C. D.; Rheingold, A. L. J. Am. Chem. Soc. 2001, $123,331$.
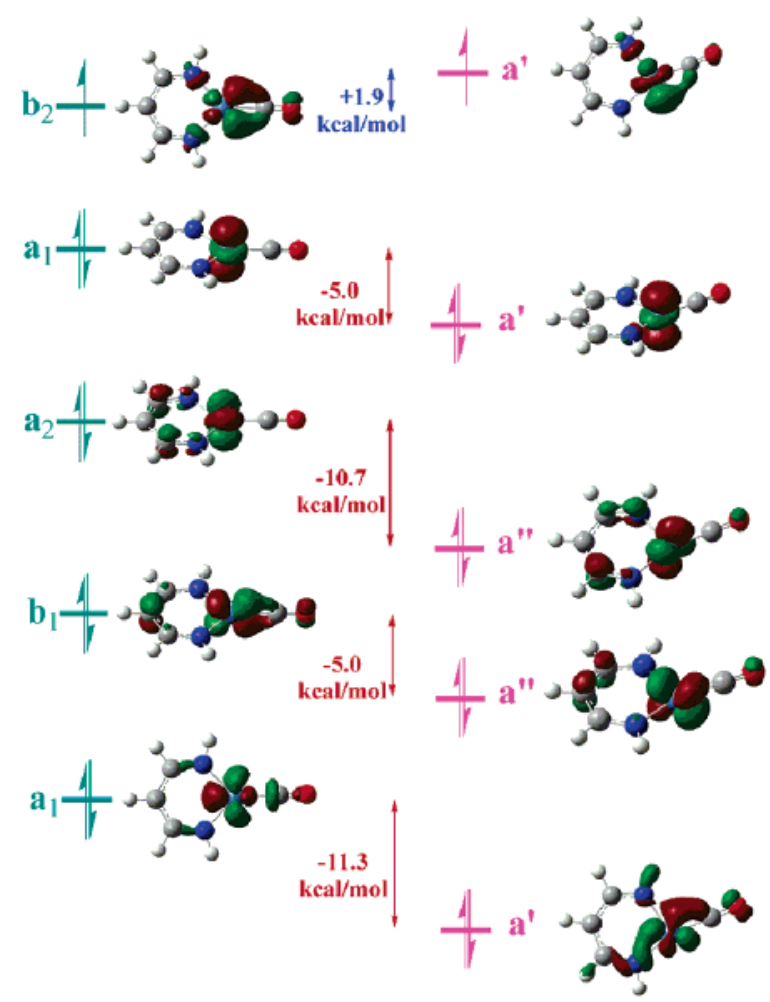

Figure 3. Molecular-orbital diagram showing the changes between Y (left, $C_{2 v}$ ) and $\mathrm{T}$ (right, $\sim C_{s}$ ) geometries of $\mathrm{L}^{\prime} \mathrm{NiCO}$.

Table 1. Structural Data for $\mathrm{L}^{\mathrm{Me}} \mathrm{Ni}(\mathrm{CO})$ and Calculated $\mathrm{L}^{\prime} \mathrm{Ni}(\mathrm{CO})$

\begin{tabular}{|c|c|c|c|c|}
\hline & \multicolumn{2}{|c|}{$\mathrm{Y}\left(C_{2 v}\right)$ calcd } & \multicolumn{2}{|c|}{$\mathrm{T}\left(C_{1}\right)$ calcd } \\
\hline & ${ }^{2} \mathrm{~B}_{1}$ & ${ }^{2} \mathrm{~B}_{2}$ & ${ }^{2} \mathrm{~A}$ & expt \\
\hline \multicolumn{5}{|c|}{ Bond Lengths ( } \\
\hline $\mathrm{Ni}-\mathrm{C}$ & 1.873 & 1.867 & 1.798 & $1.770(3)$ \\
\hline $\mathrm{C} \equiv \mathrm{O}$ & 1.165 & 1.163 & 1.166 & $1.142(3)$ \\
\hline $\mathrm{N}_{1}-\mathrm{Ni}$ & 1.937 & 1.896 & 1.902 & $1.868(2)$ \\
\hline $\mathrm{N}_{2}-\mathrm{Ni}$ & 1.937 & 1.896 & 1.930 & $1.917(2)$ \\
\hline \multicolumn{5}{|c|}{ Bond Angles (deg) } \\
\hline $\mathrm{N}_{1}-\mathrm{Ni}-\mathrm{N}_{2}$ & 95.25 & 94.48 & 96.62 & $96.41(8)$ \\
\hline $\mathrm{N}_{1}-\mathrm{Ni}-\mathrm{C}$ & 132.37 & 132.76 & 159.92 & $158.9(1)$ \\
\hline $\mathrm{N}_{2}-\mathrm{Ni}-\mathrm{C}$ & 132.37 & 132.76 & 103.46 & $104.6(1)$ \\
\hline $\mathrm{Ni}-\mathrm{C} \equiv \mathrm{O}$ & 180.00 & 180.00 & 176.37 & $177.8(2)$ \\
\hline
\end{tabular}

ROB3LYP/CEP-31G(d) level. With the symmetry enforced as $C_{2 v}$ (Y geometry), the ground state is ${ }^{2} \mathrm{~B}_{2}$. When the symmetry restriction is relaxed, geometry optimization gives a $\mathrm{T}$ ground-state geometry that is energetically favored by $7.5 \mathrm{kcal} / \mathrm{mol}$ versus the lowest energy Y-shaped geometry. The optimized geometry is in excellent agreement with the crystal structure (Table 1). The calculated d-orbital manifold shown in Figure 3 indicates that the unpaired electron is in a $\mathrm{d}_{x^{2}-y^{2}}$ type orbital (where the $z$ axis is normal to the plane of the ligands). The mixing of $\mathrm{d}_{x z} / \mathrm{d}_{y z}$ orbitals and the higher energy of $d_{x z} / d_{y z}$ orbitals than the $d_{x y}$ orbital is consistent with the observation that $\mathrm{g}_{x} \sim \mathrm{g}_{y}>\mathrm{g}_{z}$ by EPR. ${ }^{11}$ The calculated $\mathrm{C}-\mathrm{O}$ distance and stretching frequency for the T-shaped minimum of $\mathrm{L}^{\prime} \mathrm{NiCO}$ are $1.166 \AA$ and $2011 \mathrm{~cm}^{-1} .^{12}$

(11) Palmer, G. In Physical Methods in Bioinorganic Chemistry, Que, L., Ed.; University Science Books: Sausalito, CA, 1999; pp 135-137.

(12) Frequency scaled by a factor of 0.9614 , as proscribed for B3LYP calculations with double- $\zeta$-plus-polarization basis sets: Scott, A. P.; Radom, L. J. Phys. Chem. 1996, 100, 16502. 


\section{COMMUNICATION}

Analysis of the frontier molecular orbitals (Figure 3) for the $\mathrm{Y}$ and $\mathrm{T}$ geometries of $\mathrm{L}^{\prime} \mathrm{Ni}(\mathrm{CO})$ shows no evidence of a first-order Jahn-Teller effect. ${ }^{13}$ Instead, the major driving force for the $\mathrm{Y} \rightarrow \mathrm{T}$ distortion is stabilization of $\mathrm{a}_{2}$ and $\mathrm{a}_{1}$ orbitals to form $\mathrm{a}^{\prime \prime}$ and $\mathrm{a}^{\prime}$ orbitals upon bending while maintaining approximate $C_{s}$ symmetry. ${ }^{2,13,14}$ A natural bond order (NBO) analysis revealed that the atomic charge distribution is -0.6 for $\mathrm{L}^{\prime},+0.7$ for $\mathrm{Ni}$, and -0.1 for $\mathrm{CO}$. The small charge on the $\mathrm{CO}$ ligand indicates that backbonding to the carbonyl is not very strong, as expected from the experimental $\mathrm{C}-\mathrm{O}$ distance and $\mathrm{C}-\mathrm{O}$ stretching frequency. The Ni atom has 8.8 net electrons in the $\mathrm{d}$ orbitals, in agreement with the formal $\mathrm{d}^{9}$ configuration.

$\mathrm{T}$ geometries have also been observed in some recently reported three-coordinate nickel(I) complexes supported by chelating bis-phosphine ligands or alkyl ligands. ${ }^{5}$ Most notably, Warren has reported a diketiminate-nickel(I) lutidine complex with a $\mathrm{T}$ geometry like that shown here. ${ }^{5 \mathrm{~h}}$ However, the diketiminate-copper(II) complexes $\mathrm{L}^{\mathrm{Me}} \mathrm{CuCl}^{\text {6a }}$ and $\mathrm{ClL}^{\mathrm{Me}} \mathrm{CuCl}^{6 \mathrm{cc}}$ have $\mathrm{Y}$ geometries, despite the similar $\mathrm{d}^{9}$ configuration and the seeming steric accessibility of a $\mathrm{T}$ geometry. To explore the reasons for this difference, $\mathrm{L}^{\prime} \mathrm{CuCl}$ was studied using the same level of DFT as that used for the study of $\mathrm{L}^{\prime} \mathrm{Ni}(\mathrm{CO})$. For the $\mathrm{L}^{\prime} \mathrm{CuCl}$ complex, the enforced $\mathrm{Y}$ geometry $\left({ }^{2} \mathrm{~B}_{2}\right.$ electronic state) and optimized $\mathrm{T}$ geometry $\left({ }^{2} \mathrm{~A}^{\prime}\right.$ electronic state $)$ are very close in energy, with the $\mathrm{T}$ geometry slightly favored by $1.6 \mathrm{kcal} / \mathrm{mol}$. In the ground state, the distortion from the $\mathrm{Y}$ geometry is much less than that for $\mathrm{L}^{\prime} \mathrm{Ni}(\mathrm{CO})$ : the $\mathrm{N}-\mathrm{Cu}-\mathrm{Cl}$ bond angles differ by only $13.6^{\circ}$ for the $\sim C_{s}$ minimum compared to the $\mathrm{N}-\mathrm{Ni}-\mathrm{CO}$ bond angles, which differ by $56.5^{\circ}$.

$\mathrm{NBO}$ analysis shows that the charge distribution in $\mathrm{L}^{\prime} \mathrm{CuCl}$ is -0.5 for $\mathrm{L},+1.2$ for $\mathrm{Cu}$, and -0.7 for $\mathrm{Cl}$. The number of electrons in the $\mathrm{Cu} \mathrm{d}$ orbitals is 9.3 , which is considerably closer to a $\mathrm{Cu}(\mathrm{I}) \mathrm{d}^{10}$ configuration than the $8.8 \mathrm{~d}$ electrons of the Ni complex, even though the transition metal in each complex is formally $\mathrm{d}^{9}$. This agrees with EPR and XAS measurements and calculations that indicate substantial charge transfer from diketiminate to copper(II) in $\mathrm{L}^{\mathrm{Me}}$ CuSR. ${ }^{6 c, 15}$ Because a d ${ }^{10}$ configuration shows no ligand-fieldbased geometric preferences, it should favor the Y geometry. Thus, the NBO analysis suggests a simple model for understanding the difference between the nickel(I) and copper(II) complexes: $\mathrm{d}^{9}$ systems inherently favor $\mathrm{T}$ geometry, but this tendency is lessened in higher-valent complexes, where substantial charge donation from the diketiminate ligand leads to increased $\mathrm{d}^{10}$ character.

(13) Barakat, K. A.; Cundari, T. R.; Omary, M. A. J. Am. Chem. Soc. 2003 , $125,14228$.

(14) Riehl, J. F.; Jean, Y.; Eisenstein, O.; Pelissier, M. Organometallics 1992, 11, 729.

(15) All known three-coordinate copper(II) sites have diketiminate ligands ${ }^{6}$ or are in the constrained environment of metalloproteins. For a recent review on type 1 ("blue") copper sites in cupredoxins, see: Lu, Y. In Comprehensive Coordination Chemistry; McCleverty, J., Meyer, T. J., Eds.; Elsevier: Oxford, U.K., 2004; Vol. 8, p 91.
Table 2. Distorted Y Geometries for Literature Three-Coordinate Copper(II) Complexes ${ }^{6}$

\begin{tabular}{lccc}
\hline & \multicolumn{3}{c}{ bond angles (deg) } \\
\cline { 2 - 4 } & $\mathrm{N}_{1}-\mathrm{Cu}-\mathrm{N}_{2}$ & $\mathrm{~N}_{1}-\mathrm{Cu}-\mathrm{L}$ & $\mathrm{N}_{2}-\mathrm{Cu}-\mathrm{L}$ \\
\hline $\mathrm{L}^{\mathrm{Me}} \mathrm{Cu}\left(\mathrm{SCPh}_{3}\right)$ & $96.80(8)$ & $131.16(6)$ & $128.23(6)$ \\
$\mathrm{L}^{\mathrm{Me}} \mathrm{Cu}\left(\mathrm{SC}_{6} \mathrm{H}_{3} \mathrm{Me}_{2}\right)$ & $96.76(6)$ & $131.56(5)$ & $130.80(5)$ \\
$(\mathrm{ClL} \mathrm{Me}) \mathrm{CuCl}$ & $96.10(9)$ & $132.00(7)$ & $131.84(7)$ \\
$\mathrm{L}^{\mathrm{Me}} \mathrm{CuCl}$ & $97.29(8)$ & $132.32(6)$ & $130.39(6)$ \\
$\mathrm{L}^{\mathrm{Me}} \mathrm{Cu}\left(\mathrm{SCPh}_{2} \mathrm{CH}_{2} \mathrm{OMe}\right)$ & $96.23(6)$ & $135.9(1)$ & $126.6(1)$ \\
$\mathrm{L}^{\mathrm{Me}} \mathrm{Cu}\left(\mathrm{OC}_{6} \mathrm{H}_{3} \mathrm{Me}_{2}\right)$ & $96.31(8)$ & $138.76(7)$ & $123.98(7)$ \\
$\mathrm{L}^{\mathrm{Me}} \mathrm{Cu}\left(\mathrm{OC}_{6} \mathrm{H}_{4} \mathrm{OMe}\right)$ & $96.7(1)$ & $140.9(1)$ & $122.1(1)$ \\
$\left(\mathrm{ClL}{ }^{\mathrm{Me}}\right) \mathrm{Cu}\left(\mathrm{OC}_{6} \mathrm{H}_{4}{ }^{t} \mathrm{Bu}\right)^{a}$ & $96.26(9)$ & $145.72(8)$ & $117.77(8)$ \\
\multicolumn{3}{c}{${ }^{a}$ Low-temperature structure given here; the space group changes at higher } \\
temperature. ${ }^{6 \mathrm{~d}}$
\end{tabular}

Interestingly, several literature $\beta$-diketiminate-copper(II) complexes have more or less distorted Y geometries. ${ }^{6}$ The $\mathrm{N}-\mathrm{Cu}-\mathrm{X}$ bond angles are summarized in Table 2. The complexes containing OR ligands are closer to a T geometry than those with SR and Cl ligands. Steric factors certainly play a part in determining the geometries of complexes of bulky thiolate and aryloxide ligands. However, calculations indicate that an electronic effect is present as well. Geometry optimization of $\mathrm{L}^{\prime} \mathrm{CuOH}$ and $\mathrm{L}^{\prime} \mathrm{CuSH}$ gives a more substantial distortion in the former $\left[\Delta(\mathrm{N}-\mathrm{Cu}-\mathrm{X})=16^{\circ}(\mathrm{X}=\mathrm{OH})\right.$; $\left.0^{\circ}(\mathrm{X}=\mathrm{SH})\right]$. Calculated bond angle changes reflect the inherent electronic impetus for the $\mathrm{Y}$ to $\mathrm{T}$ distortion in the absence of steric effects, and the calculated $\Delta(\mathrm{N}-\mathrm{Cu}-\mathrm{X})$ trend is consistent with that observed experimentally. In the context of the above model, the difference may again be due to differential charge donation: NBO calculated charges on $\mathrm{Cu}$ are +1.2 for $\mathrm{OH}$ and $\mathrm{Cl}$ models and +1.0 for the thiolate model. Hence, the NBO analysis suggests that the thiolate ligand donates more charge density to copper(II) than the aryloxide ligand, giving a copper atom with greater $\mathrm{d}^{10}$ character, resulting in a Y geometry.

In conclusion, we have isolated a nickel(I) carbonyl complex that displays a striking $\mathrm{T}$ geometry, which is ascribed to electronic effects. Literature copper(II) complexes do not show the same geometry except with very electronegative ligands, and we propose that the geometric differences can be explained through differential charge donation from the ligands to the metal.

Acknowledgment. Support for this research from the National Science Foundation (Grant CHE-0134658 to P.L.H.; Grant CHE-0309811 to T.R.C.) and the University of Rochester (Weissberger Fellowship to N.A.E.) is acknowledged. We thank William Tolman for helpful comments. Several of the calculations were performed on the UNT computational chemistry resource supported by the NSF (Grant CHE-0342824).

Supporting Information Available: Synthetic, spectroscopic, crystallographic, and computational details (in CIF and PDF formats). This material is available free of charge via the Internet at http://pubs.acs.org.

IC0510213 